\title{
Sustaining Arts Programs in Public Education
}

\author{
David Dunstan \\ University of Southern California
}

\begin{abstract}
The purpose of this qualitative research case study was to investigate leadership and funding decisions that determine key factors responsible for sustaining arts programs in public schools. While the educational climate, financial constraints, and standardized testing continue to impact arts programs in public education, Eastland High School, the site of this case study, managed to sustain its visual and performing arts program. The foundation of this research study was shaped around understanding the key factors that sustained the arts program at Eastland High School. A qualitative lens utilized three research questions that investigated arts programs at the school, leadership decisions that supported the arts program, and funding decisions made at the site. Data triangulation was used to identify several emerging themes relevant to the three research questions. The implications of this case study indicated collaborative leadership and resourceful funding decisions sustain viable arts programs in public schools.
\end{abstract}

Keywords: leadership, visual and performing arts, public schools, funding decisions

The current educational landscape threatens the survival of arts programs in public education throughout the United States. Current trends in education indicate public schools have increasingly narrowed their curriculums to enroll underachieving students in additional remedial reading and math courses with less time available to pursue visual and performing arts (Beveridge, 2010). Political and societal pressures have forced school districts to improve academic performance among students struggling to improve their reading and math scores on standardized tests. As a result of these shifting priorities and accountability demands, many school leaders have reduced their arts programs (Anne, 2010). Accountability to increase standardized testing results impacts all stakeholders, from teachers and administrators to leaders at the lo- cal, state, and national branches of government (Anne, 2010; Beveridge, 2010). Amid bureaucratic levels of accountability at schools, administrative leaders, department leaders, and leadership teams make decisions that impact their visual and performing arts programs. However, some school leaders continue to maintain viable arts programs in the face of these changes. This research study investigated the administrative and funding decisions that contribute to the success of a viable arts program at Eastland High School.

\section{Benefits of Arts Programs}

The arts have the potential to promote motivation, confidence, and social skills among children and teens (Alejandro, 1994; Creedon, 2011; Tredway \& Wheat, 2010). Children have the potential to embrace a lifelong appreciation for the arts through school curriculums that support comprehensive, interdisciplinary arts programs. As children enter their teen years, their involvement in arts programs provides opportunities to collaborate and interact with others, develop leadership skills, and become global citizens. Alejandro (1994), Creedon (2011), and Olshansky (2008) agreed that arts programs provide academic and social benefits for at-risk students.

Creedon (2011) observed that at-risk students in urban schools responded favorably to arts programs. He argued their participation in a multidisciplinary arts program provides students with an educational solution that counters stress they may develop from other classes, interactions with peers and teachers, their families, and urban neighborhoods. Music, dance, theater, and visual arts have the capacity to connect productively with the emotional and physical needs of children. Olshansky (2008) found at-risk students experienced significant improvement on reading and writing tests in a controlled case study that measured the use of visual literacy to support instruction and the learning process. 
In a case study with elementary students, Alejandro (1994) found that her methodology using visual literacy in her English language arts curriculum effectively motivated students to improve their reading and writing skills. Students created colorful visual narratives to demonstrate their reading comprehension, and they produced artistic paintings to aid in memorization of new vocabulary. These students posted significant gains on standardized tests, and findings from her study contributed to a growing awareness among students, faculty, parents, and other stakeholders of the benefits of arts in education (Alejandro, 1994).

Arts programs are also experiencing success in alternative curriculum formats at charter schools. The growing charter school movement, which began in 1992, accounts for over 4,000 schools throughout the nation (Zimmer \& Buddin, 2009). Given the constraints evident in traditional public schools, parents, educators, and community leaders have embraced autonomy in a concentrated effort to develop curriculum and educational missions at their charter schools (Gratto, 2002). In her analysis of alternative arts programs at charter schools, Gratto (2002) found arts curriculums produce favorable learning outcomes among both at-risk and high-achieving students.

An education grounded in the arts elevates the capacity for students to collaborate with each other and foster metacognitive abilities across all subjects (Music, 2010). A comprehensive arts education empowers students to share their learning experiences across the curriculum. Understanding the value of learning through active participation in an arts program that is integrated across the curriculum provides life-long benefits for students (Heilig, Cole, \& Aguilar, 2010; Juno, 2010). Findings from recent research studies support the assertion that students enrolled in interdisciplinary curriculum involving core subjects and the arts enjoyed notable academic outcomes (Gratto, 2002; Kratochvil, 2009; Juno, 2010). Moreover, it seems arts programs are gaining in popularity. Barone and Eisner (2006) cited the emergence of artsbased educational research, while several case studies found visual literacy continues to expand its appeal beyond elementary education and gain wider acceptance at secondary schools (Bryce, 2012; Carpenter \& Cifuentes, 2011; Frey \& Fisher, 2008).

\section{Arts and Student Achievement}

Active participation in arts education programs has produced positive learning outcomes with interdisciplinary curriculum tied to standardized testing and student academic achievement. Vygotsky recognized that arts contribute to the learning process and construction of knowledge (Gullatt, 2008). An interdisciplinary nature is evident in successful arts programs that bind together curricular themes and encourage cross-department collaboration. Recent case studies have documented success at public school arts programs and their impact on academic achievement among disadvantaged students and long-term contributions to low-income neighborhoods through community partnerships (Kratochvil, 2009; Noblit, Corbett, Wilson, \& McKinney, 2008; Olshansky, 2008; Tredway \& Wheat, 2010).

Case studies investigating at-risk, low-income, and struggling students enrolled in arts-integrated courses at public schools found their standardized test scores increased (Kratochvil, 2009; Gullatt, 2008; Rabkin \& Redmond, 2003; Strickland, 2008). Skills gained in dramatic arts and music programs encouraged students to apply their knowledge and motivation to learn other core subjects (Gullat, 2008). Alternatively, patterns of discouraging enrollment in arts courses were noticeable among at-risk and low-income students who had dropped out of school. According to Strickland (2008), high school dropouts reported that they spent significantly less time enrolled in arts courses and more time in remedial instruction to learn math and reading skills.

Students living in low socio-economic neighborhoods have performed academically better on standardized tests when actively enrolled in arts courses (Rabkin \& Redmond, 2003). Rabkin and Redmond's (2003) research found current educational leadership tends to ignore research studies that document the social and academic benefits that at-risk and lowincome students gain from their participations in arts programs. At 23 schools in Chicago with artintegrated programs, case studies found noticeable increases in reading and math standardized test scores among students identified as disadvantaged and atrisk to drop out (Rabkin \& Redmond, 2003). Rabkin and Redmond also discovered low-income, at-risk students showed more motivation to participate and learn at schools when involved in interdisciplinary arts programs.

Alejandro (1994), Creedon (2011), and Tredway and Wheat (2010) agreed that the arts contribute toward student achievement. In a case study with her second grade students, Alenandro documented significant gains in reading and writing on standardized tests after integrating visual arts and visual literacy into her curriculum (Creedon, 2011). Tredway and Wheat found the principal at East Oakland School of the Arts 
reported significant academic improvement and success among students when he fully integrated arts into a school-wide curriculum and made a long-term commitment to support the arts program. Their research found that a single leader who makes an arts program an active element in an interdisciplinary curriculum yields academic gains in student achievement. Additionally, a single leader with exceptional social and political skills can advocate for interdisciplinary collaboration among faculty to accept an arts curriculum (Tredway \& Wheat, 2010). Trends evident in the literature suggest academic achievement increased at schools where administrators supported the arts (Farbman, Wolf, \& Sherlock, 2013; Freedman, 2011; Kratochvil, 2009; Olshansky, 2008).

In her case study at a middle school in California, Kratochvil (2009) found sustained long-term leadership and faculty collaboration contributed to the successful school-wide integration of arts across all subjects. The school underwent a collaborative transformative process to develop a school-wide action plan to support a dance program. The success of the dance program defined the culture of the school with intrinsic and extrinsic benefits for students, parents, and community members (Kratochvil, 2009). However, measuring success and achievement in performing and visual arts disciplines requires a mixture of professional arts experience and objective reflection with respect to the individual artistic achievement of each student (Davis, 2008). Although recent case studies show pockets of success throughout the educational landscape, the literature reflects the ongoing struggles to maintain and sustain arts programs in public schools.

\section{Funding for Arts Programs}

The decline in traditional public school funding sources, which arts programs relied on for financial support, has motivated the implementation of prudent fiscal accountability, innovative fundraising initiatives, and community partnerships. Title I funds were originally intended to support schools with lowincome students across all subjects, including the arts, and they have become the financial lifeline to support remedial intervention courses and improve standardized test results that meet Annual Measurement Achievement Objectives (Stillwell-Parvensky, 2011). In response to less availability of Title I funds to support arts programs, recent research has focused attention on arts programs with leaders that cultivate financial investment through community partnerships (Anne, 2010; Beveridge, 2010; Sabol, 2010). As traditional funding sources decline, school leaders seeking to support their arts programs have proactively developed partnerships with local and national arts organizations as well as coalitions with social media and corporate organizations to recognize artistic talent among students (Music, 2010; Tredway \& Wheat, 2010).

The growth of charter and magnet schools has triggered a concurrent emergence of arts academies designed with progressive mission statements and visionary leadership teams that support arts programs in local communities (Zimmer \& Buddin, 2009). Gratto (2002) found successful arts programs at alternative public schools. One example is Orange County High School of Arts in Santa Ana, California, which is a specialized high school with a comprehensive arts curriculum and active community partnerships. Business and community partnerships among arts organizations represent a core element of charter schools, alternative schools, and specialized schools throughout the nation (Gratto, 2002).

Castaneda and Rowe (2006) conducted an analysis of the 10-year Los Angeles Unified School District Arts Prototype program, and they found schools with high academic reputations and consistent leadership were more inclined to develop strong partnerships with arts organizations. Trends among the 200 arts organizations that partnered with Los Angeles Unified schools suggested that successful partnerships involve schools with an arts-focused professional development plan and an interdisciplinary arts curriculum. In addition, the schools implemented an active calendar of art exhibits, musicals, and theater performances that appealed to parents and the local community (Castaneda \& Rowe, 2006). These partnerships provided an ongoing culture of collaboration between the arts programs and the community.

According to Castaneda and Rowe (2006), schools with higher Academic Performance Index (API) scores secured stronger financial partnerships. Through their partnerships with schools, arts organizations contributed to professional development, sponsored exhibitions, and maintained the visibility of the school and its artistic achievements within the community. While schools with lower API scores in Program Improvement (PI) status received Title I funds to support low-income and disadvantaged students, the authors found school leaders tended to divert Title I funds toward intervention programs to improve test scores and ignore arts programs. As a consequence, Castaneda and Rowe found underperforming schools lacked the leadership required to develop community partnerships with organizations that could support 
arts programs and contribute positive outcomes to the neighborhood.

Arts education programs in public schools face a restrictive climate of accountability and financial constraints. Alejandro (1994), Creedon (2011), and Olshansky (2008) found effective school leaders advocated for the benefits of arts programs and their influence on student achievement. Intersecting political and societal agendas and issues will determine the future sustainability and success of arts education programs in K-12 curriculums. The history of arts education reflects an ongoing, persistent struggle to remain relevant in the current climate of accountability and highstakes testing. Policy makers, educational leaders, and teachers represent a cross-section of stakeholders with the capacity to advocate for arts programs in public schools that serve disadvantaged students in low socioeconomic neighborhoods (Anne, 2010; Creedon, 2011; Kratochvil, 2009; Tredway \& Wheat, 2010). Sustaining arts education programs in public schools requires investigating and justifying the benefits of arts programs and their impact on academic student achievement in the current era of high stakes standardized testing and accountability.

This review of literature identified the significance of school leaders who embrace arts education and support the integration of interdisciplinary arts programs across core subject curriculums to enhance academic achievement (Anne, 2010; Castaneda \& Rowe, 2006; Gratto, 2002; Music, 2010; Tredway \& Wheat, 2010). While past case studies and research acknowledged the benefits of arts education programs in K-12 public schools, a gap in the scholarly literature fails to sufficiently identify and explain the factors involved in sustaining arts education programs (Anne, 2010; Beveridge, 2010; Creedon, 2011). The review of literature indicated a gap existed regarding how leadership and funding decisions impact arts programs in public schools (Merriam, 2009). This case study was conducted to investigate and understand the key factors in sustaining an arts program by utilizing three research questions:

- What are the arts programs that exist at Eastland High School?

- How does leadership at Eastland High School support arts?

- How are funding decisions made at Eastland High School?

\section{Methods}

\section{Research Design}

The research design used a qualitative case study approach to collect and analyze data required to understand the phenomenon explored in the three research questions that defined the foundation of the research study (Creswell, 2009). The rationale behind the survey, interview protocol, and observation protocol was developed from the literature. Data triangulation was achieved by using four data collection instruments to provide four distinct data sources to address the three research questions.

A conceptual framework, displayed in Figure 1, was developed to understand the system of concepts, assumptions, expectations, beliefs, and theories that supported and informed the research (Maxwell, 2009). A viable arts program involves two essential interconnected components that contribute to effective leadership: financial constraints and accountability. As expressed in the conceptual framework, the term viable indicates that an enduring arts program has longevity, capable leadership, funding, and other foundational, influential components.

The conceptual framework reveals how faculty make decisions and how those decisions influence the culture, climate, and leadership at the school. The model shows how the two inputs determine school leadership decisions and impact resources and priorities. Stakeholders, partnerships, facilities, time, and funding impact the use of resources and priorities involved in a successful, viable arts program. The conceptual framework also indicates how multiple aspects of the school infrastructure, including the curriculum, instructional components, and the staffing, contribute to a viable arts program. The conceptual framework provided a road map with a visual representation of a viable arts program to guide the research study (Maxwell, 2013).

\section{Setting}

The setting for this case study was selected based upon several criteria:

- The presence of a viable visual and performing arts program.

- Graduate placement with awards, recognition, and success of graduates.

- Three years of operation and longevity with the same leadership team. 


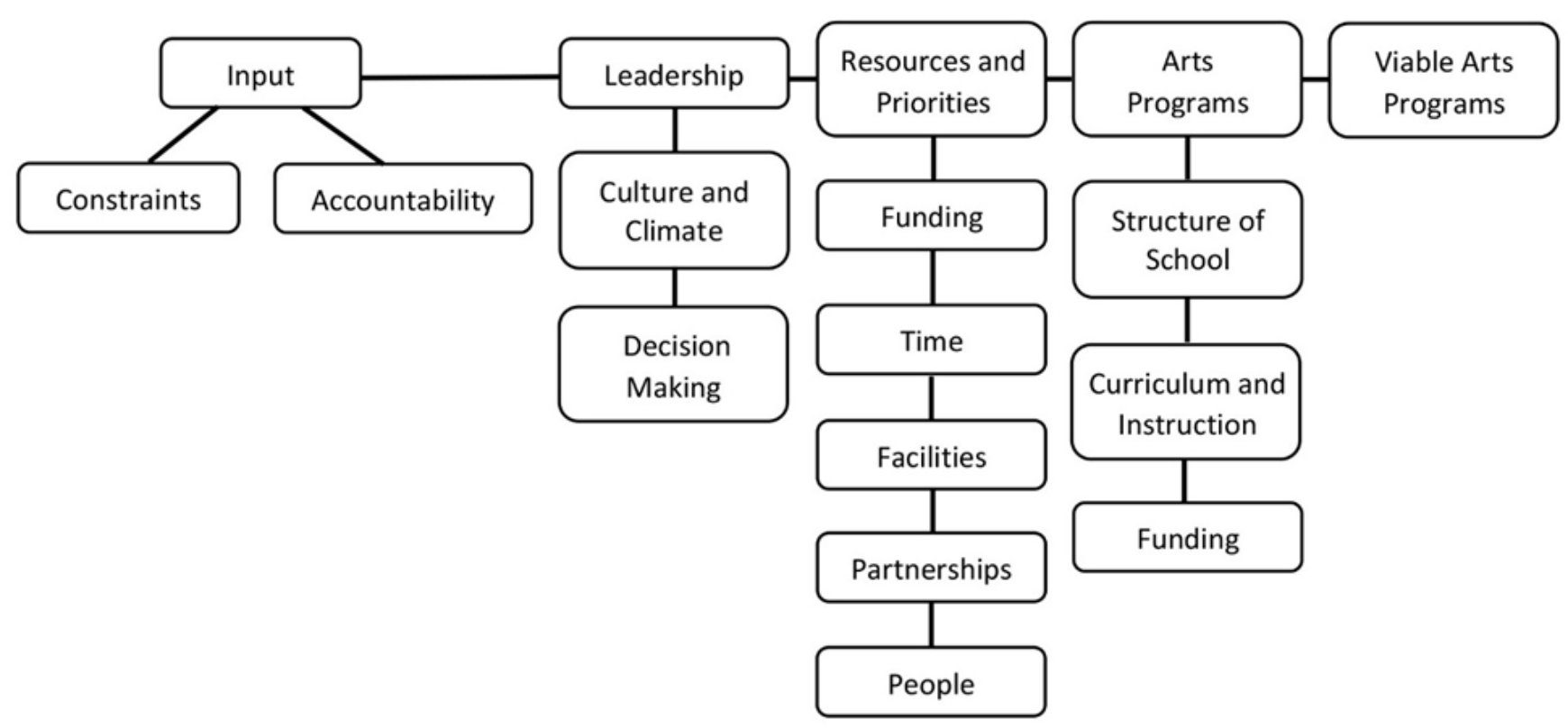

Figure 1. Viable arts program conceptual framework.

- Similar Schools Ranking of 8, 9, or 10 (with a viable arts program).

- Diverse student body.

- Evidence of planning as a visual and performing arts school.

Eastland High School, the selected school site, is one of eight comprehensive high schools in a rural, urban district, located in California. The school has approximately 2,600 students, 100 teachers, and five administrators. The language of the majority of students is English-only, while 12\% of the population is designated as ELLs. Over 50\% of students are Hispanic, $31 \%$ are African-American, $14 \%$ are White, and $2 \%$ are Asian/Filipino/Pacific Islanders. The majority of students are economically disadvantaged, and over $80 \%$ of students qualify for free or reduced price lunch.

Eastland has an active visual and performing arts program that met the school site criteria required to participate in the research study. The arts program has maintained a stable leadership team that has guided it in successful operation since the school opened in 2005. The program includes an annual awards and district-wide student recognition system, a diverse student body, and consistent organizational and crosscurricular planning. The visual and performing arts program has also received numerous accolades. Robbie, the department chair of the visual and performing arts program, was one of the co-founders of the school in 2005. Under her leadership since 2005, Robbie has improved the quality and reputation of the visual and performing arts program among students, parents, and alumni. In 2009, when the school moved to a newly constructed campus, the school opened a new theater with modern technology to serve the campus and local community. Since 2012-13, the Eastland High School theater has hosted musicals, dramas, dances, symphony performances and art exhibitions.

\section{Procedure}

A review of documents preceded the implementation of a school-wide survey and a structured sequence of interviews and observations. The varied approach to data collection reinforced reliability and validity of the data (Creswell, 2009). Participants in the study were informed of the purpose of the study. The researcher discussed with participants the research questions, interview questions, data collection instruments, and timeline to conduct the data collection process. Each participant was identified with a pseudonym to protect his or her privacy. Participants were assured that the research study was objective and purposeful.

The two visual and performing arts department chairs, Robbie and Ted, shared historical details about the visual and performing arts program at Eastland High School. Their interviews provided the research study with an opportunity to capture the history of the program (Creswell, 2009). To address Creswell's (2009) caution about interviews occurring outside their natural setting, interviews with each participant 
occurred on campus in their natural classroom settings. The interviews and observations complemented each other as separate sources of data for triangulation. The researcher wrote field notes based on the context of each interview, adding observations to complement transcribed interviews with additional descriptive data (Bogdan \& Biklen, 2003). The review of documents and implementation of surveys, observations, and interviews transpired at one site during a limited time in fall 2013. Therefore, the responses were unique and reflect a designated time period among participants in the study.

\section{Data Analysis}

Data from an analytical review of documents, transcribed interviews, observation notes, and survey results underwent a thematic coding process conducted by the guidelines recommended by Creswell (2009). Bolman and Deal's (2003) four frames, or perspectives, of understanding and analyzing the workings of organizations were used to analyze the data. The four frames, identified as the structural, human resource, political, and symbolic, informed the thematic interpretation of the data to examine the organizational aspects of the arts program at the school (Bolman \& Deal, 2003). For the purpose of this case study, the structural frame applies to the organizational structure of the school and departments in the school. The human resource frame concerns the interpersonal relationships and needs of teachers, administrators, parents, and students within the school organization. The political frame concerns the bureaucratic nature at Eastland High School and how each stakeholder and department navigates the political structure of the organization. The symbolic frame refers to the reputation of the school and the symbols that define its culture as a brand and institution within the community (Bolman \& Deal, 2003).

\section{Results and Discussion}

While the review of literature acknowledged declines in school budgets and other constraints to maintain arts programs, the literature also discussed research studies regarding viable arts programs and key factors responsible for their success in the current educational climate (Anne, 2010; Beveridge, 2010; Music, 2010; Sabol, 2010; Tredway \& Wheat, 2010). Funding, leadership, partnerships, promising practices, and student achievement through arts programs were explored in the literature and applied to the design of data collection instruments. Each topic influenced the themes and trends found in the data analysis. Data was coded into three emergent thematic categories, finding that leaders at the site embraced a collaborative leadership style, developed community partnerships, and implemented resourceful funding decisions. These themes represented the three key factors responsible for sustaining the visual and performing arts program at Eastland High School.

The first theme recognized the strength of collaborative leadership that cultivated support for the arts programs at Eastland High School. The principal and the leaders of the visual and performing arts departments showed a consistent effort to collaborate, contributing toward a supportive culture in the campus community. A collaborative culture contributes toward the longevity of arts programs in public schools (Robert, 2010). Bolman and Deal (2008) recognized the importance of leadership in the four frames of an organization.

Findings from this research study found that department leaders Kate, Robbie, and Ted cultivated significant social and political capital as leaders of their departments. Each leader developed his or her individual effective, visionary leadership style. While Kratochvil (2009) found consistent leadership and faculty collaboration helped arts programs succeed across the curriculum, leaders with longevity in their positions held more influence. The findings complemented evidence reported in the literature review, which recognized the importance of leaders capable of building social and political capital among all stakeholders to support and sustain arts programs (Anne, 2010; Castaneda \& Rowe, 2006; Gratto, 2002; Music, 2010; Tredway \& Wheat, 2010).

Interviews and observations captured an example of collaborative leadership at an interdisciplinary meeting on October 23, 2013. Robbie led the meeting with visible support from Kate and other administrators and department chairs. She sought to connect core subjects with the arts curriculum through common themes and collaboration. As a successful art teacher with a highly regarded reputation among her colleagues, students, and parents, Robbie demonstrated she was a capable instructional leader who influenced positive learning outcomes at interdisciplinary art department meetings. Robbie acknowledged the need for teachers to recognize emerging trends with the California Common Core State Standards. She encouraged faculty to proactively collaborate with each other to support the college and career themes found in the new standards.

A second example of collaborative leadership involved the school's interdisciplinary project Wasteland: 
Turning Illegally Dumped Waste into Art. The schoolwide project initially involved the visual and performing arts faculty, their partnership with the local museum, and approximately 660 visual and performing arts students who took action against illegal dumping in the local community. Students collected objects from trash dumpsites to create works of recycled art. Exceptional pieces of recycled art premiered at the annual Eastland High School visual and performing arts showcase and at the local museum. As more departments and faculty integrated learning objectives from Wasteland into their curriculum, the project eventually motivated over 2,000 students and approximately 60 faculty members to become involved in supportive activities. Learning outcomes from the Wasteland project inspired stakeholders at all school levels and the local museum to support the subsequent Crosswinds interdisciplinary project, which underscored the importance of collaborative leadership as a central theme that emerged from the data analysis.

A second theme found school leaders developed community partnerships with local organizations and museums to support the arts. The Wasteland and Crosswinds projects represented two interdisciplinary art projects financed with grants through the local museum and other organizations. Without community partnerships, Eastland High School and the local community may never have experienced the benefits gained from each project. The significance of community partnerships that support public school arts programs was discussed in the literature review (Castaneda \& Rowe, 2006; Music, 2010; Sabol, 2010; Tredway \& Wheat, 2010). The interdisciplinary art projects, marching band performances, and plays produced in the new school theater represented work achieved through a collaborative culture and strong leadership that resonated with the community. Each project and event defined symbolic activities that defined the school culture and further strengthened the reputation of the school in the local community.

A clear example of community partnerships was evident within the performing arts program, which holds a strong reputation in the local community. The marching band and color guard were considered symbols of pride at Eastland High School and in the city. Their parades, dance performances, and pep rallies at football games, tournaments, and local events defined members' reputations as high quality leaders and representatives of the performing arts program. Leaders of the arts program at Eastland High School found it mutually beneficial to forge long-term community partnerships with the local museum, civic leaders, and the annual fair. In an interview, Saul, a performing arts leader, explained the significance of the marching band and its role as a symbol of pride in the local community:

We're the pride of the school. We keep the school moving, kind of like the heartbeat of the school when we play at football games and at the pep rallies. We want to be a presence on campus to show the students that high school is very important.

The third theme involved the resourceful funding decisions made among leaders to support the visual and performing arts program. While Eastland High School remains under program improvement and receives Title I funds to close the achievement gap, leaders of the visual and performing arts program implemented resourceful strategies to raise funds through parent-led booster programs and community partnerships. Ted, Robbie, and Saul expressed concerns regarding the narrowing of core curriculum with fewer ninth grade students enrolled in arts courses. While previous research indicated many Title I public schools tend to exclude at-risk, low-income students from the arts in favor of enrolling them in reading and math courses (Sabol, 2010; Stillwell-Parvensky, 2011), evidence from this case study offered a counterpoint. Eastland High School has maintained high enrollment numbers for marching bands, color guards, drama courses, and visual arts courses. Given the success and growth of the visual and performing arts program, as traditional funding sources decline, implementing resourceful funding decisions represented a significant theme responsible to sustain the arts programs at Eastland High School.

The resourceful funding theme complements the collaborative leadership and community partnership themes. As the 2013-14 academic year concluded, raising funds through the booster club, community partnerships, and grants represented a necessary financial decision to sustain the visual and performing arts program at Eastland High School. Reflecting on each theme that emerged from this case study, collaborative leadership, community partnerships, and resourceful funding decisions represented the three essential components evident in the arts program.

Given the evidence triangulated from site documents, survey, interviews, and observations, a need exists to create and implement an arts education plan at the site. Eastland High School is not a fully integrated arts school. The visual and performing arts program provides a developing arts pathway with approximately 600 out of 2500 students enrolled in arts courses. An organizational goal among the visual 
and performing arts leadership team seeks to transform their operations with an arts pathway into a formal academy with financial and creative autonomy based on the original vision of the school as the main visual and performing arts school in the district.

While this case study found two interdisciplinary art projects cultivated school-wide support, a visual and performing arts academy may limit future schoolwide, cross-department support among faculty unaffiliated with the academy. Given the financial constraints and declining budgets available to support the arts, educational leaders have learned to cultivate community partnerships and implement resourceful funding decisions. Robbie and Ted believe a visual and performing arts academy would ensure financial and creative autonomy for the arts programs.

Results from data triangulation collected from the site documents, survey, interviews, and observations found school leadership should reevaluate its organizational approach to support arts education at Eastland High School. Based on the results, administrators and faculty should consider the creation of a unified arts education policy that clearly supports arts education at the site. An arts education plan would define the role of the visual and performing arts program at Eastland High School and determine the pros and cons of a proposed visual and performing arts academy.

From a structural perspective, the visual and performing arts program has hired the best and most qualified instructors. The structural frame of an organization informs all stakeholders of its expectations and goals and connects with the human resource, political, and symbolic frames (Bolman \& Deal, 2008). While many aspects of the organizational structure were evident, including supportive administrative leadership and interdisciplinary collaboration, the evidence suggested that the visual and performing arts program should revisit its structural design and support the creation of a school-wide arts education plan. A strong organizational structure, with goals and objectives, would influence the other three frames.

\section{Limitations}

The limitations in this qualitative case study included conditions that the researcher could not control. The case study was limited by its geographic location and the time constraints to collect data. While the researcher conducted the case study at a site where he also worked as a teacher, the principal and school leadership team held the power to approve or deny his research proposal. To address the limitations, the researcher reflected on research bias and his direct and indirect influence on responses from participants (Maxwell, 2013).

\section{Implications and Recommendations}

This case study provided a qualitative lens to understand how effective leadership and funding decisions support a viable arts program that empowers students and faculty to share learning experiences through the arts and across an interdisciplinary curriculum (Creswell, 2009). Sustaining the arts in public education is increasingly relevant as schools wrestle with financial constraints and external pressure to increase standardized test scores in math and reading. Educators in visual and performing arts programs found students enrolled in art, music, and drama programs develop an intrinsic motivation to succeed across all disciplines (Posnick-Goodwin, 2013).

A viable arts program provides life-long benefits for students. This research study determined that the arts program has elevated the social and political status of Eastland High School among students, faculty, parents, and other stakeholders in the local community. Results from this case study found administrative, departmental, and faculty leadership exercised a consistent, collaborative leadership style responsible for the successful visual and performing arts program at Eastland High School.

Given the current challenges confronting educational leaders to adopt the California Common Core State Standards, the arts have endured as a source of stability throughout the history of public education. Findings from this case study will contribute to the scholarly literature devoted toward understanding the benefits that students and school communities experience as a result of effective leadership that supports and sustains arts programs. While financial constraints, standardized testing, accountability demands, educational reform, and other interconnected challenges remain visible on the horizon, effective, collaborative leadership emerged as the essential factor responsible to influence productive funding decisions that sustain viable arts programs in public schools.

Based on evidence analyzed from the data, implications from this research study include a need to further investigate the role of leadership in viable arts programs at public schools. Findings from the case study suggested effective leadership, with a consistent motivation to support the arts, represented an essential element required to sustain arts programs in pub- 
lic education. Data analysis and exploration of the findings encouraged five recommendations for future research:

- Investigate Title I funding in public education with a research focus to understand their availability to support visual and performing arts programs.

- Explore how public schools with viable arts programs integrate the arts across the curriculum and improve math and reading skills.

- Investigate the positive learning outcomes among children enrolled in student-centered arts curriculums at public schools that integrate arts across an interdisciplinary curriculum.

- Align arts education with a school-wide and district-wide instructional plan.

- Improve the visibility of the arts program in the local community to strengthen community partnerships with local museums, organizations, and businesses that share an interest to financially support the arts.

\section{References}

Alejandro, A. (1994). Like happy dreams: Integrating visual arts, writing, and reading. Language Arts, 71(1), 12-12. Retrieved from http://search.proquest.com/ docview $/ 196877974$ ?accountid=14749

Anne, C. G. (2010). No child left behind in art education policy: A review of key recommendations for arts language revisions. Arts Education Policy Review, 111(1), 8-15. Retrieved from http:// search.proquest.com/docview/609259357? accountid=14749

Barone, T., \& Eisner, E. (2006). Arts-based educational research. In J. L. Green, G. Camilli, \& P. B. Elmore (Eds.), Handbook of complementary methods in education research (pp. 95-109). Mahwah, NJ: Erlbaum.

Beveridge, T. (2010). No Child Left Behind and fine arts classes. Arts Education Policy Review, 111(1), 4-7. Retrieved from http:/ / search.proquest.com/docview/609292495? accountid=14749

Bogdan, R. C., \& Biklen, S. K. (2003). Qualitative research for education: An introduction to theory and methods ( $5^{\text {th }}$ ed.). New Jersey: Pearson.

Bolman, L. G., \& Deal, T. E. (2008). Reframing organizations: Artistry, choice and leadership (4th ed.). San Francisco: Jossey Bass.

Bryce, N. (2012). "Mano a mano": Arts-based nonfiction literacy and content area learning. Language Arts, 89(3), 179-193. Retrieved from http:/ / search.proquest.com/ docview $/ 913135312$ ?accountid $=14749$
Carpenter, B. S., \& Cifuentes, L. (2011). Visual culture and literacy online: Image galleries as sites of learning. Art Education, 64(4), 33-40. Retrieved from http:// search.proquest.com/ docview $/ 1022336929$ ?accountid=14749

Castaneda, L. W., \& Rowe, M. K. (2006). Partnerships in arts education: An examination of factors predicting schools' use of arts organization. Journal of Arts, Management, Law and Society. 36(1), 7-23.

Creedon, D (2011). Fight the stress of urban education with the arts. Phi Delta Kappan, 92(6), 34-36.

Creswell, J. W. (2009). Research design: Qualitative, quantitative and mixed methods approaches ( $3^{\text {rd }}$ ed.). Thousand Oaks, CA: Sage Publications, Inc.

Farbman, D., Wolf, D. P., \& Sherlock, D. (2013). Advancing arts education through an expanded school day: Lessons from five schools. Boston, MA: National Center on Time \& Learning.

Freedman, K. (2011). Leadership in art education: Taking action in schools and communities. Art Education, 64(2), 40-45.

Frey, N., \& Fisher, D. (Eds.). (2008). Teaching visual literacy: Using comic books, graphic novels, anime, cartoons, and more to develop comprehension and thinking skills. Thousand Oaks, California: Corwin Press.

Gratto, S. (2002). Arts education in alternative school formats. Arts Education Policy Review, 103(5), 17-24.

Gullatt, D (2008). Enhancing student learning through arts integration: Implications for the profession. The High School Journal, 91(4), 12-25.

Heilig, J. V., Cole, H., \& Aguilar, A. (2010). From Dewey to No Child Left Behind: The evolution and devolution of public arts education. Arts Education Policy Review, 111(4), 136-145. Retrieved from http:/ / search.proquest.com/docview/759963251 accountid=14749

Juno, S. V. (2010). Seeing is believing: Making our learning through the arts visible. In D. M. Donahue \& J. Stuart (Eds.), Artful teaching: Integrating the arts for understanding across the curriculum, K-8 (71-

78). New York, NY: Teachers College Press.

Kratochvil, K. R. (2009). The survival of arts education in the NCLB era: A case study of one K-8th grade arts-focused charter school in a California program improvement school district (Doctoral dissertation). Retrieved from ProQuest Dissertations and Theses. (304859703).

Maxwell, J. A. (2013). Qualitative research design: An interactive approach ( $3^{\text {rd }}$ ed.). Los Angeles, CA: Sage Publications, Inc.

Merriam, S. B. (2009). Qualitative research: A guide to design and implementation. San Francisco: Jossey-Bass.

Music, L. (2010). Creating alliances for arts learning and arts integration. In D. M. Donahue \& J. Stuart (Eds.), Artful teaching: Integrating the arts for understanding across the curriculum, K-8, (pp. 45-56). New York, NY: Teachers College Press. 
Noblit, G. W., Corbett, H. D., Wilson, B. L., \& McKinney, M. (2008). Creating and sustaining arts-based school reform: The A+ schools program. New York, NY: Routledge.

Olshansky, B. (2008). The power of pictures: Creating pathways to literacy through art. San Francisco, CA: Jossey-Bass.

Posnick-Goodwin, S. (2013). 5 reasons to bring back the arts. California Educator, 18(1), 9-13.

Rabkin, N., \& Redmond, R. (2003). The arts make a difference. Educational Leadership, 63(5), 60-64.

Robert, D. G. (2010). Should I stay or should I go? Factors that influence the retention, turnover, and attrition of K-12 music teachers in the United States. Arts Education Policy Review, 111(3), 112-121. Retrieved from http:// search.proquest.com/docview/746431811? accountid=14749

Sabol, R. F. (2010). No Child Left Behind: A study of its impact on art education. West Lafayette, IN: Purdue University.

Stillwell-Parvensky, M. (2011). Reforming Title I: Closing the academic achievement gap for disadvantaged students (Unpublished master's thesis). Harvard Kennedy School, Harvard, MA

Strickland, P. (2008). Teachers arts education: Integrating arts in the classroom (Doctoral dissertation). Retrieved from ProQuest Dissertations and Theses. (304381266)

Tredway, L., \& Wheat, R. (2010). Leadership for and in the arts. In D. M. Donahue \& J. Stuart (Eds.), Artful teaching: Integrating the arts for understanding across the curriculum, K-8 (pp. 71-78). New York, NY: Teachers College Press.

Zimmer, R., \& Buddin, R. (2009). Is charter school competition in California improving the performance of traditional public schools? Public Administration Review, 69(5), 831-845.

Retrieved from http://search.proquest.com docview $/ 197175914$ ?accountid=14749 